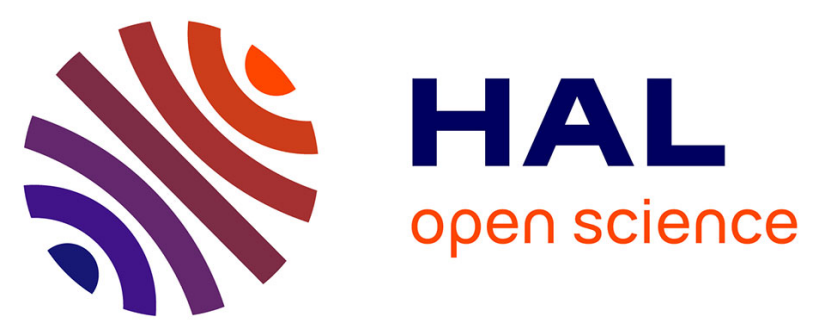

\title{
PHYSICAL PROPERTIES OF COMPOUNDS NiS2-xSex WITH PYRITE STRUCTURE: METAL-NON METAL TRANSITION, EVIDENCE FOR THE EXISTENCE OF AN ANTIFERROMAGNETIC METALLIC PHASE
}

G. Krill, P. Panissod, M. Lapierre, F. Gautier, Cédric Robert Robert, G. Czjzek, J. Fink, H. Schmidt, R. Kuentzler

\section{- To cite this version:}

G. Krill, P. Panissod, M. Lapierre, F. Gautier, Cédric Robert Robert, et al.. PHYSICAL PROPERTIES OF COMPOUNDS NiS2-xSex WITH PYRITE STRUCTURE : METAL-NON METAL TRANSITION, EVIDENCE FOR THE EXISTENCE OF AN ANTIFERROMAGNETIC METALLIC PHASE. Journal de Physique Colloques, 1976, 37 (C4), pp.C4-23-C4-27. 10.1051/jphyscol:1976404 . jpa-00216518

\section{HAL Id: jpa-00216518 https://hal.science/jpa-00216518}

Submitted on 1 Jan 1976

HAL is a multi-disciplinary open access archive for the deposit and dissemination of scientific research documents, whether they are published or not. The documents may come from teaching and research institutions in France or abroad, or from public or private research centers.
L'archive ouverte pluridisciplinaire HAL, est destinée au dépôt et à la diffusion de documents scientifiques de niveau recherche, publiés ou non, émanant des établissements d'enseignement et de recherche français ou étrangers, des laboratoires publics ou privés. 


\title{
PHYSICAL PROPERTIES OF COMPOUNDS NiS ${ }_{2-x} \mathrm{Se}_{x}$ WITH PYRITE STRUCTURE : METAL-NON METAL TRANSITION, EVIDENCE FOR THE EXISTENCE OF AN ANTIFERROMAGNETIC METALLIC PHASE
}

\author{
G. KRILL, P. PANISSOD, M. F. LAPIERRE. F. GAUTIER and C. ROBERT \\ Laboratoire de Structure Electronique des Solides \\ (E. R. A. 100), 4, rue Blaise-Pascal, 67000 Strasbourg, France
}

G. CZJZEK, J. FINK and H. SCHMIDT

Kernforschungszentrum. Institut für Angewandte Kernphysik 7500 Karlsruhe. Postfach 3640, Deutschland

\section{R. KUENTZLER}

Institut de Physique. Laboratoire Pierre Weiss

3, rue de l'Université, 67084 Strasbourg Cedex, France

\begin{abstract}
Résumé. - Nous discutons dans cet article les propriétés physiques des composés mixtes $\mathrm{NiS}_{2-x} \mathrm{Se}_{x}$ à structure pyrite. Ce système présente une transition isolant-métal pour $x \sim 0,45$; cette transition est interprétée dans un schéma de Mott-Hubbard. D'après nos résultats expérimentaux (susceptibilité magnétique, R. M. N. sur ${ }^{77} \mathrm{Se}$, effet Mössbauer sur ${ }^{61 \mathrm{Ni}}$ et expérience de diffraction de neutrons), nous montrons qu'une phase antiferromagnétique métallique (A. F. M.) existe dans ce système dans la gamme $0,45 \leqslant x \leqslant 1$. Les propriétés magnétiques particulières de la phase $\mathrm{A}$. F. $\mathrm{M}$. sont discutées à l'aide d'un modèle d'environnement local déterminant l'état magnétique des atomes de nickel.
\end{abstract}

Abstract. - We discuss the physical properties of mixed compounds $\mathrm{NiS}_{2-x} \mathrm{Se}_{x}$. In this system for $x \sim 0.45$ an insulator-metal transition occurs which is interpreted in the sense of the model of Mott and Hubbard. Our experimental results (susceptibility, N. M. R. with 77Se, Mössbauer spectroscopy with ${ }^{61} \mathrm{Ni}$ and neutron diffraction) demonstrate the existence of an antiferromagnetic metallic phase (AFM) in the range of concentrations $0.45 \leqslant x \leqslant 1$. The magnetic properties of the AFM phase are discussed in terms of a model which implies a strong influence of the local environment on the magnetic state of nickel atoms.

1. Introduction. - Nickel disulphide and nickel diselenide both crystallize in the pyrite structure and the intermediate compounds $\mathrm{NiS}_{2-x} \mathrm{Se}_{x}$ can be obtained in the whole range $0 \leqslant x \leqslant 2$ by the usual chemical synthesis which yields insulating nickel disulphide. $\mathrm{NiS}_{2}$ has been studied extensively in the last few years [1 to 7] since its physical properties are in agreement with the predictions of the Mott-Hubbard model [8, 9] for correlation effects in a narrow half-filled band: (a) $\mathrm{NiS}_{2}$ is an insulator $[1,2]$, an insulator-metal transition occurs at high pressure ( $\left.P_{0} \sim 30 \mathrm{kbar}\right)[3]$, and (c) antiferromagnetic ordering was found below $45 \mathrm{~K}[4]$.

In a one-electron model the nickel dichalcogenides $\left(\mathrm{NiS}_{2}, \mathrm{NiSe}_{2}\right.$ and $\left.\mathrm{NiTe} \mathrm{T}_{2}\right)$ are characterized by a halffilled conduction band built mainly from $\mathrm{Ni} 3 \mathrm{~d}-$ orbitals of $\Gamma_{12}\left(\mathrm{e}_{\mathrm{g}}\right)$ symmetry and chalcogen $\mathrm{sp}^{3}$ orbitals. The importance of correlation effects is determined by the ratio $W / U$ where $W$ is the band width and $U$ the correlation energy. If $W / U \ll 1$ the conduction band is split, and an insulating state is obtained. This appears to be the case in $\mathrm{NiS}_{2}$ where the hybridization between $\mathrm{Ni}-\mathrm{e}_{\mathrm{g}}$ states and $\mathrm{S}-\mathrm{sp}^{3}$ states presumably is small. Thus the $\Gamma_{12}$ band is narrow and has mostly d-character.

In. $\mathrm{NiSe}_{2}$, on the other hand, stronger $\mathrm{e}_{\mathrm{g}}-\mathrm{sp}^{3}$ mixing leads to a wider $\Gamma_{12}$ band and thus to a considerable reduction of correlation effects $(W / U>1)$ such that $\mathrm{NiSe}_{2}$ is a paramagnetic metal as expected in the framework of a one-electron picture.

In the mixed compounds $\mathrm{NiS}_{2-x} \mathrm{Se}_{x}$ an insulatormetal transition occurs as $\mathrm{Se}$ is substituted for $\mathrm{S}[3,10]$. The changes of the physical properties associated with the transition, as well as the concentration dependence of these properties in the insulating and in the metallic phase were the subject of our study, a brief summary of which is given in the present paper. A detailed report will be presented elsewhere [11].

Firstly the changes of the electrical resistivity induced by substitution of $\mathrm{Se}$ for $\mathrm{S}$ in $\mathrm{NiS}_{2}$ are reviewed and 
compared to the changes observed when another metal such as copper is substituted for nickel in $\mathrm{NiS}_{2}$ or when nickel vacancies are introduced by high-pressure synthesis [5]. In the second chapter we discuss the magnetic properties of $\mathrm{NiS}_{2-x} \mathrm{Se}_{x}$ in the metallic phase (3.1) and in the insulating phase (3.2). The existence of an antiferromagnetic metallic phase for $0.45 \leqslant x \leqslant 1$ is demonstrated. In this phase influences of local environment appear to determine the magnetic state of nickel atoms.

2. Insulator-metal transition. - In their study of mixed compounds $\mathrm{NiS}_{2-x} \mathrm{Se}_{x}$ Wilson and Pitt [3] have shown that the pressure-induced insulator-metal transition is observed at room temperature for $x=\mathbf{0 . 4}$, but not for $x=0.8$. For $x<0.4$, the critical pressure $P_{0}$ for this transition decreases with increasing Se content (Fig. 1). Resistivity measurements on single

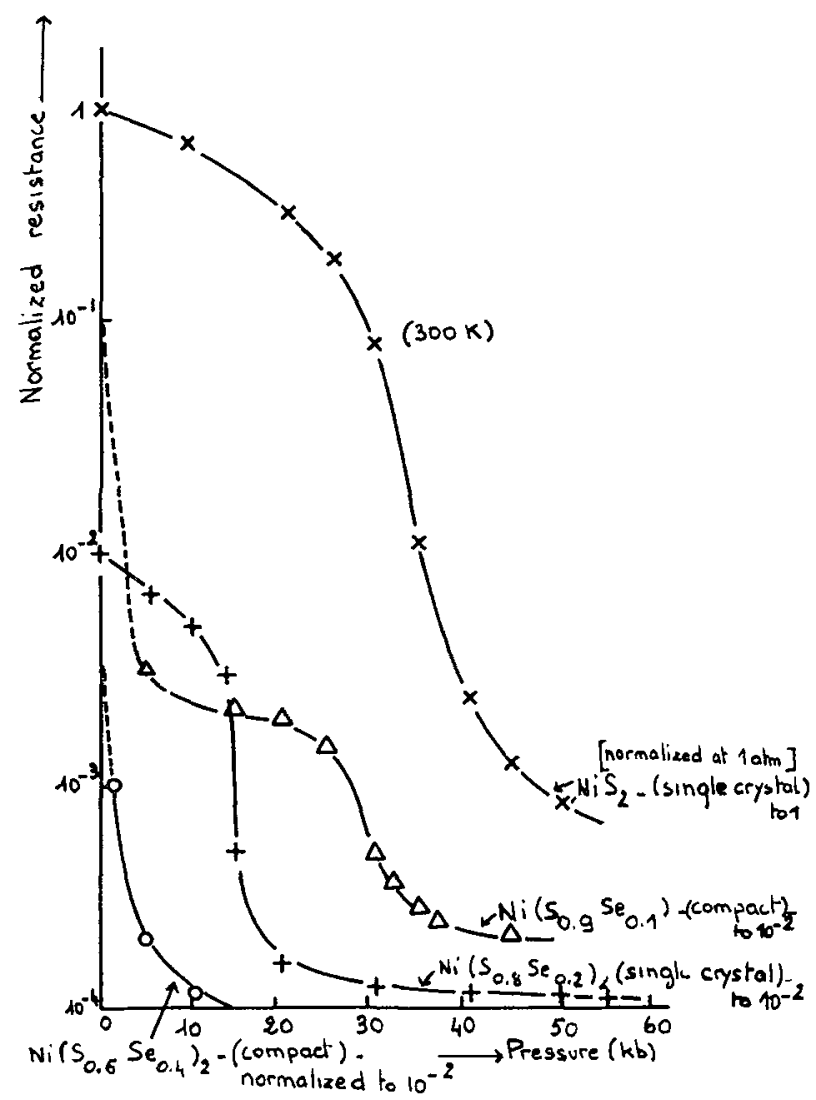

FrG. 1. - Resistivity versus pressure $(T=300 \mathrm{~K})$ for $\mathrm{NiS}_{2-x} \mathrm{Se}_{x}$ from [3].

crystals by Jarrett et al. [10] indicated a transition to the metallic state at $0 \mathrm{~K}$ near $x=0.45$. These results, in particular the concentration dependence of $P_{0}$, are consistent with the view that the broadening of the $\Gamma_{12}{ }^{-}$ band associated with increasing Se content leads to the insulator-metal transition in these compounds.

There is a superficial similarity to the changes observed when copper is substituted for nickel in mixed compounds $\mathrm{Ni}_{1-\delta} \mathrm{Cu}_{\delta} \mathrm{S}_{2}$ [7], or when nickel vacancies are introduced in compounds $\mathrm{Ni}_{1-\delta} \mathrm{S}_{1.9}[6,7]$ (we also use the notation $\mathrm{NiS}_{x}$, with $x>1.9$, as in ref. [7]), in that in both cases an insulator-metal transition is observed. However, in these compounds, the transition occurs at a much lower impurity concentration (for vacancies : at $\delta \sim 0.04$, for $\mathrm{Cu}$ : at $\delta \sim 0.03$, compared to $x_{\text {crit }} \sim 0.45$ which corresponds to a Se-concentration near 0.22). Furthermore, the critical pressure $P_{0}$ is practically unaffected by these impurities on the nickel sublattice (Figure 2 shows the case of

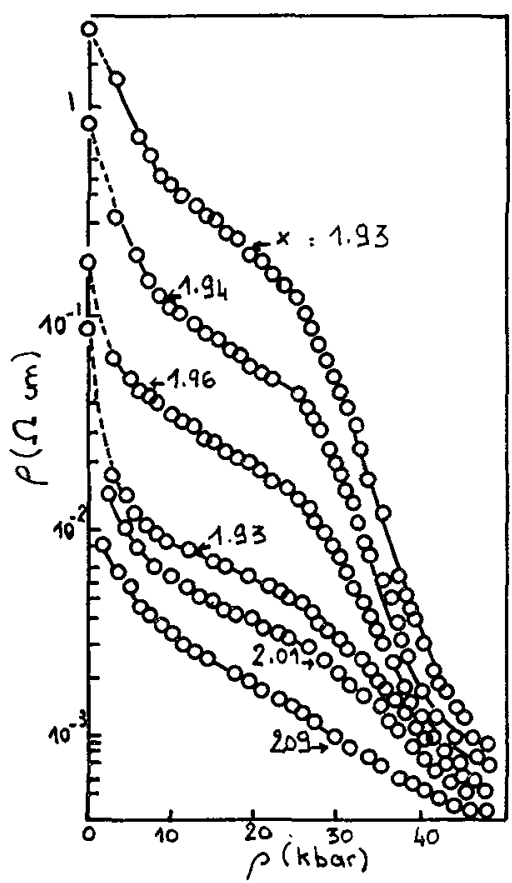

FIG. 2. - Resistivity versus pressure $(T=300 \mathrm{~K})$ for $\mathrm{NiS}_{x}$ (short notation for $\mathrm{Ni}_{1-\delta} \mathrm{S}_{1.9,}$, with $\left.x=(1-\delta) / 1.9\right)$.

vacancies, the results for $\mathrm{Ni}_{1-\delta} \mathrm{Cu}_{\delta} \mathrm{S}_{2}$ are quite similar [7]), and the resistivity in the metallic state is much larger $\left(\rho(4 \mathrm{~K}) \sim 10^{-2} \Omega \mathrm{cm}\right)$ than for metallic $\mathrm{NiS}_{2-x} \mathrm{Se}_{x}\left(\rho(4 \mathrm{~K}) \sim 10^{-4} \Omega \mathrm{cm}\right)$.

In these last mentioned cases, the transition has to be ascribed to a different mechanism, namely the changed filling of the $\Gamma_{12}$-band which should lead to a rapid transition to a metallic state. Influences of local impurity potentials may lead to the differences between the phenomena observed in these compounds and those found in $\mathrm{NiS}_{2-x} \mathrm{Se}_{x}$.

In all cases, a sudden decrease of the lattice parameter is observed at the insulator-metal transition, irrespective of its occurrence due to a change of concentration [6] or due to pressure [12].

3. Magnetic properties of $\mathrm{NiS}_{2-x} \mathrm{Se}_{x} \cdot-3.1$ ExISTENCE OF THE ANTIFERROMAGNETIC METALLIC PHASE (A. F. M.). - The existence of an antiferromagnetic phase in the metallic state has been predicted in the 
framework of a Hartree-Fock approach to half-filled bands of strongly correlated electrons [13]. The schematic phase diagram deduced from such calculations exhibits at $T=0 \mathrm{~K}$ successively antiferromagnetic insulating (A.F. I.), antiferromagnetic metallic (A. F. M.) and paramagnetic metallic (P. M.) phases as $W / U$ increases. Our experimental investigations of $\mathrm{NiS}_{2-x} \mathrm{Se}_{x}$ clearly demonstrate the existence of an A. F. M. phase for $0.45 \leqslant x \leqslant 1:(a)$ the disappearence of the ${ }^{77} \mathrm{Se} N . \mathrm{M}: \mathrm{R}$. line below a certain temperature $T_{\mathrm{N}}(x)$ gave the first indication of magnetic ordering; $(b)$ at the same temperatures $T_{\mathrm{N}}(x)$ small anomalies of the susceptibility, similar to those observed at the transition to antiferromagnetic ordering in some transition metal alloys, were found; (c) the magnetic hyperfine splitting of ${ }^{61} \mathrm{Ni}-\mathrm{Mössbauer}$ spectra demonstrated the presence of static magnetic moments at nickel atoms, and $(d)$ by neutron diffraction we proved the existence of long range antiferromagnetic ordering (figure 3 , results for $x=0.6$ have been

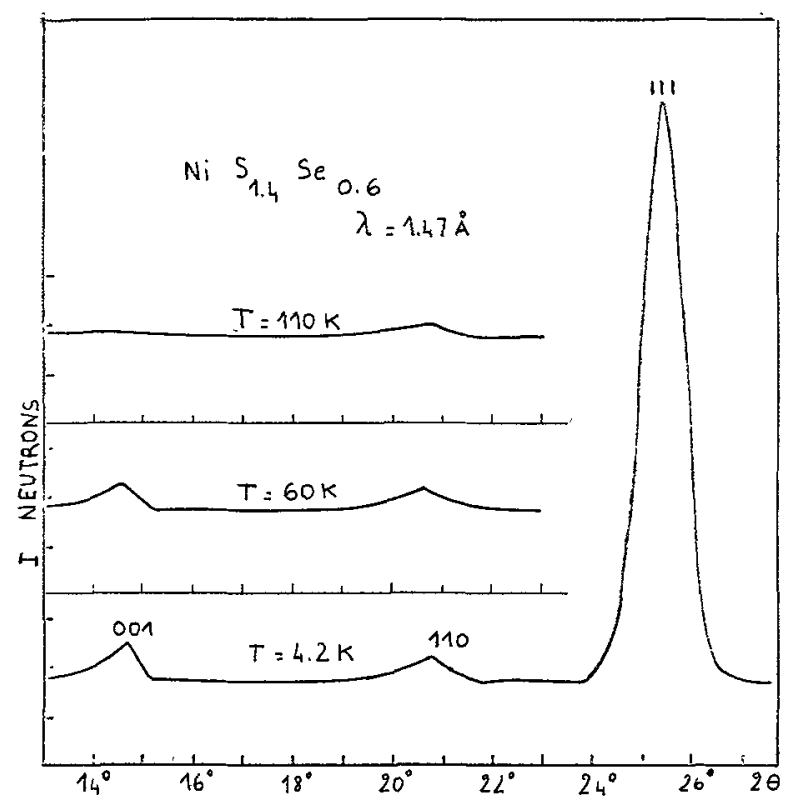

FIG. 3. - Neutron diffraction patterns of $\mathrm{NiS}_{1.4} \mathrm{Se}_{0.6 .}(001)$ and (110) are magnetic lines corresponding to an antiferromagnetic structure of the first kind on a fac lattice.

reported in ref. [14]). The combined results of Mössbauer spectroscopy and neutron diffraction show that the spin arrangement is noncollinear and of the same type as in antiferromagnetic $\mathrm{NiS}_{2}[7]$.

From susceptibility and specific heat measurements we deduce a large value for the density of states at the Fermi surface $: n\left(\varepsilon_{\mathrm{F}}\right)=10$ states/(eV.spin). This result substantiates the proposition of a narrow conduction band of d-character.

The Mössbauer spectra give us evidence for the existence of some magnetic inhomogeneity in the AFM phase : They can not be fitted if we assume a unique value of the magnetic hyperfine field at all nickel sites, nor if we allow for a distribution of fields centered about one average value. Good fits are obtained if we assume two inequivalent nickel sites distinguished by different hyperfine fields. For brevity we will denote the sites of larger hyperfine fields as $\beta$-sites (and the low-field sites as $\alpha$-sites). As shown in figure 4 , the

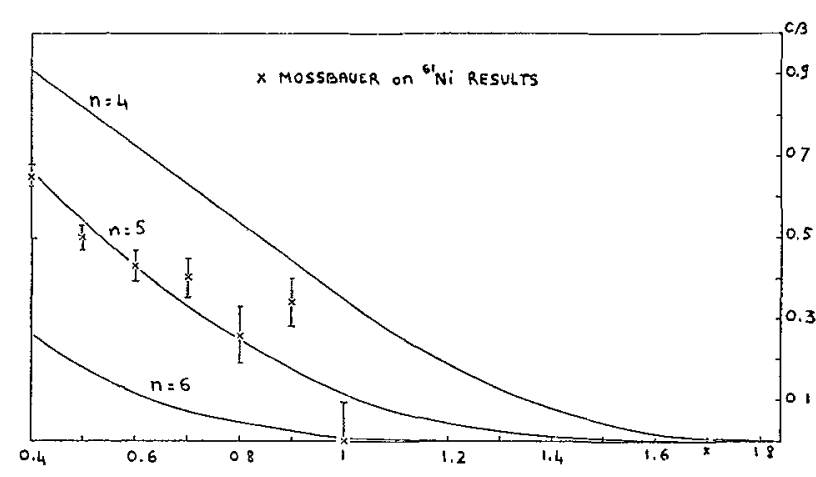

FIG. 4. - Concentration dependence of the fraction of $\beta$-sites $\left(\mathrm{c}_{\beta}\right)$ in the AFM phase of $\mathrm{NiS}_{2-x} \mathrm{Se}_{x}$. Solid curves are the calculated probabilities for a $\mathrm{Ni}$ atom to have at least $n(=4,5$ or 6$)$ $\mathrm{S}$ atoms among its nearest six chalcogen neighbours.

fraction $c_{\beta}$ of $\beta$-sites deduced from the Mössbauer spectra for concentrations in the range $0.4 \leqslant x \leqslant 1.0$ agrees with the calculated fraction of those nickel atoms having at least five sulphur atoms among their nearest six neighbours (assuming random distribution of $S$ and Se atoms). Furthermore, the small values of the hyperfine fields on $\alpha$-sites may be interpreted as indicat-

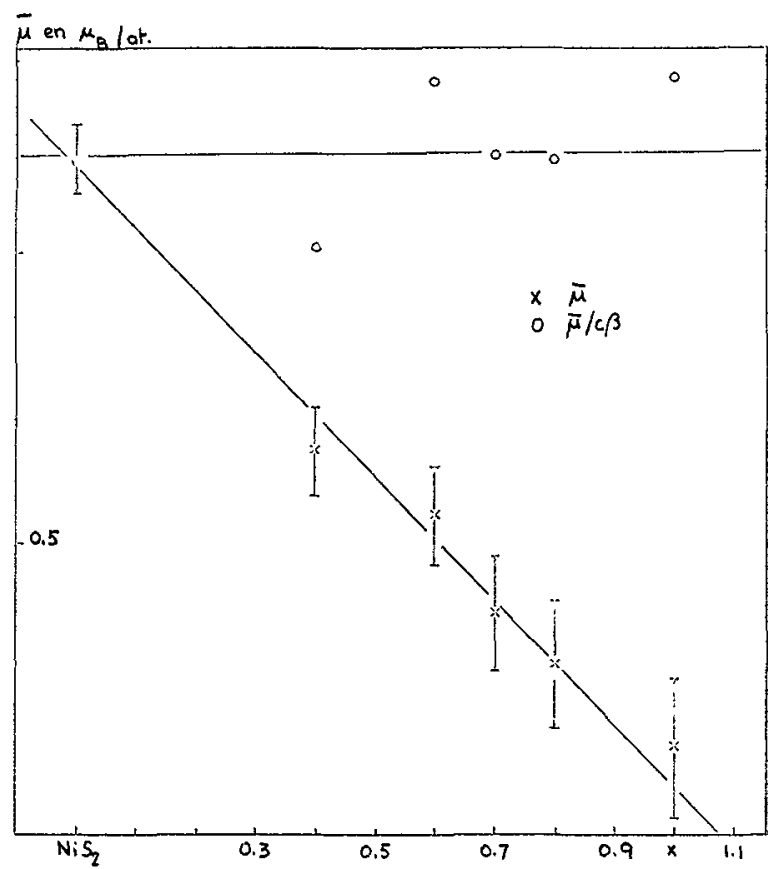

FIG. 5. - Average magnetic moment per nickel atom. The upper curve shows the moment per nickel on $\beta$-sites if $\mu_{\mathrm{Ni}, \alpha}=0$ is assumed. 
ing supertransferred hyperfine fields. If we thus assume that only nickel atoms on $\beta$-sites carry a magnetic moment, we derive from the average moments $\bar{\mu}(x)$. determined by neutron diffraction a constant value $\mu_{\mathrm{Ni}, \beta}=\bar{\mu}(x) / c_{\beta}(x) \simeq 1.2 \mu_{\mathrm{B}}$ (Fig. 5), equal to the nickel moment in $\mathrm{NiS}_{2}$. This model of local environment effects is analogous to that of Jaccarino and Walker [15] for the appearance of a local moment on iron impurities in transition metal alloys.

3.2 The insulating PHASE. - The magnetic structures occuring in the insulating phase of $\mathrm{NiS}_{2-x} \mathrm{Se}_{x}$ $(0 \leqslant x \leqslant 0.45)$ were investigated by Mössbauer spectroscopy and by neutron diffraction. As in the AFM phase, two inequivalent nickel sites were seen in the Mössbauer spectra. Between $\mathrm{NiS}_{2}$ and $\mathrm{NiS}_{1.8} \mathrm{Se}_{0.2}$ only minor changes of the transition temperatures and of the hyperfine interactions at ${ }^{61} \mathrm{Ni}$ nuclei were found. For higher Se-concentrations the Néel temperature rises rapidly with $x$. From the data obtained so far it appears possible that the curves $T_{\mathrm{N}}(x)$ for the metallic and for the semiconducting phases may join smoothly at the phase boundary.

The transition from antiferromagnetic to weakly ferromagnetic ordering which for $x \leqslant 0.2$ leads to a pronounced increase of the magnetic hyperfine field $H_{\mathrm{hf}}$ [7] is hardly detectable in the temperature dependence of $H_{\mathrm{hf}}$ for $\mathrm{NiS}_{1.7} \mathrm{Se}_{0.3}$. At this concentration the transition temperature seems to be considerably lower $(16 \pm 3 \mathrm{~K})$ than in $\mathrm{NiS}_{2}(31 \mathrm{~K})$.

In $\mathrm{NiS}_{1.6} \mathrm{Se}_{0.4}$ we find a continuous variation of the magnetic hyperfine fields with temperature in the range from $1.2 \mathrm{~K}$ to $55 \mathrm{~K}$. No weak ferromagnetic moment was detected down to $4.2 \mathrm{~K}$. As shown in figure 6 , the temperature dependence of $H_{\mathrm{hf}}$ deviates significantly from that of the nickel moments deter-

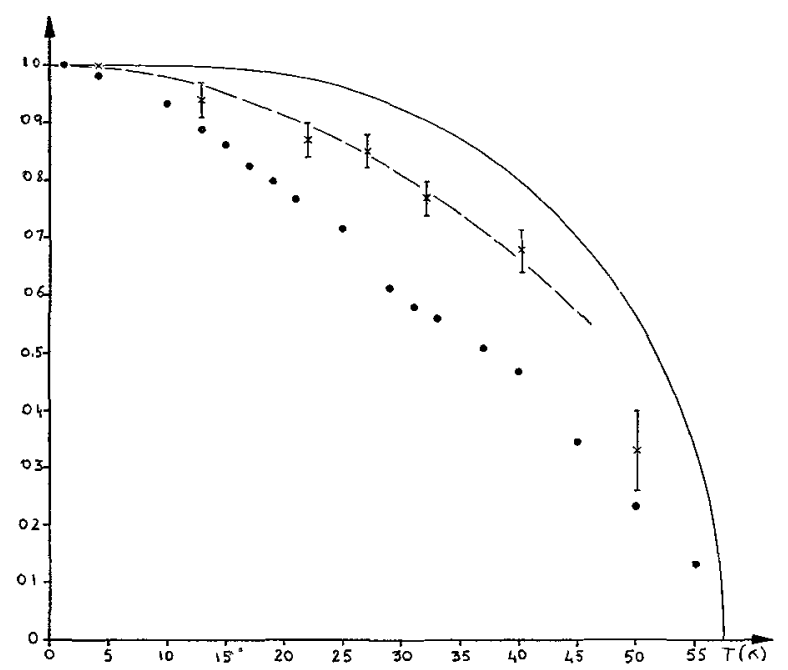

FIG. 6. - Temperature dependence of the average magnetic moment per $\mathrm{Ni}$ atom in $\mathrm{NiS}_{1.6} \mathrm{Se}_{0.4}$ (A. F. I. phase), determined by neutron diffraction, and of the average magnetic hyperfine field at ${ }^{61} \mathrm{Ni}$ nuclei. mined by neutron diffraction. In this sample the effective quadrupole coupling constant

$$
v_{Q}^{\text {eff }}=\frac{1}{2} e^{2} q Q \cdot\left(3 \cos ^{2} \theta-1\right)
$$

also varies continuously with temperature $(\theta$ is the angle between the symmetry axis and the direction of $H_{\mathrm{hf}}$ ). These results can be reconciled by the assumption of a continuous rotation with temperature of the nickel moments with respect to the symmetry axis in conjunction with anisotropic hyperfine fields. Similar results were obtained for $x=0.45$. Thus, the magnetic behaviour in this range of Se concentrations differs considerably from that of compounds with $x \leqslant 0.2$. The situation at intermediate concentrations is not yet understood completely.

For $x=0.5$, the insulator-metal transition was determined by resistivity measurements to occur in the temperature range 35 to $65 \mathrm{~K}$, however, no significant changes of the hyperfine interactions at ${ }^{61} \mathrm{Ni}$ nuclei concurrent with this transition were observed.

4. Conclusions. - The principal results of our experiments are summarized in the phase diagram in figure 7 including those modifications with respect

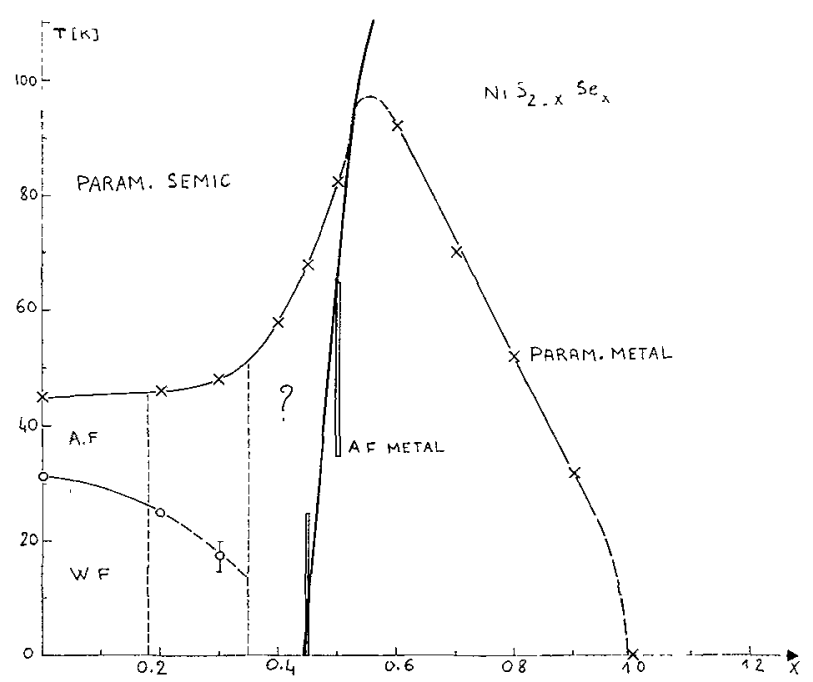

Frg. 7. - Phase diagram of $\mathrm{NiS}_{2-x} \mathrm{Se}_{x}$.

to the diagram proposed by Jarrett et al. [10] which follow from the present work. Further experiments are required in order to precise the boundaries of the diagram, and especially to answer the question for the occurrence of a critical point which might be expected near $x \sim 0.55$ and $T \sim 120 \mathrm{~K}$.

Our data support the interpretation of the insulatormetal transition occurring in the system $\mathrm{NiS}_{2-x} \mathrm{Se}_{x}$ as a Mott-Hubbard transition associated with increasing band width.

The phenomena observed in the AFM phase can be rationalized by a model of local environment effects on the magnetic state of nickel atoms. 


\section{References}

[1] Brther, T. A., Bouchard, R. S., Cloud, W. H., Donohue, P. C. and Siemons, W., Inorg. Chem. 7 (1968) 2208.

[2] Kautz, R. L., Dresselhaus, M. S., Adler, D. and Linz, A., Phys. Rev. B 6 (1972) 20.

[3] Wilson, J. A. and Prrt, G. D., Phil. Mag. 23 (1971) 1297.

[4] Hastings, J. M. and Corliss, L. M., IBM J. Res. Dev. 14 (1970) 227.

[5] Gautier, F., KriLl, G., Lapierre, M. F. and Robert, C., Solid State Commun. 11 (1972) 1201.

[6] -, J. Phys. C: Sol. St. Phys. 6 (1973) L 320.

[7] Krill, G., Lapierre, M. F., Gautier, G., Robert, C., Czjzek, G., Fink, J. and Schmidt, H., J. Phys. $C$ : Sol. St. Phys, 9 (1976) 761.

[8] Motr, N. F., Metal Insulator Transitions (London : Taylor and Francis) 1974.

[9] Hubbard, J., Proc. $R$ Soc. A 277 (1964) 237; A 281401.
[10] Bouchard, R. J., Gillson, J. L. and JARRETT, H. S., Mater. Res. Bull. 8 (1973) 489.

Jarrett, H. S., Bouchard, R. J., Gullson, J. L., Jones, G. A., Marcus, S. M. and WeIHer, J. F., Mater. Res. Bull. 8 (1973) 877.

[11] Krill, G., Panissod, P., Lapierre, M. F., Gautier, F., Robert, C., CzJzek, G., Fink, J., Schmidt, H. and KUENTZLER, R., to be published.

[12] Endo, S., Mitsui, T. and Mryadal, T., Phys, Lett. A 46 (1973) 29.

[13] Cyrot, M. and Lacour Gayet, P., Solid State Commun. 11 (1973) 1767.

[14] Plumier, R. and KRILl, G., J. Physique Lett. 36 (1975) L-249.

[15] Jaccarino, V. and Walker, L. R., Phys. Rev. Lett. 15 (1965) 258. 